Vol. 12(3), pp. 97-103, July-September 2020

DOI: $10.5897 / J A S D 2020.0579$

Article Number: 6BE8B8E64888

ISSN 2141-2189

Copyright (C) 2020

Author(s) retain the copyright of this article

http://www.academicjournlas.org/JASD
ACADEMIC JOURNALS

Journal of African Studies and Development

\title{
Neglect and discrimination: A tale of Zimbabwe's inaccessible public transport system
}

\author{
Thembelihle Ndebele \\ Disability Resources and Advocacy Trust, Zimbabwe. \\ Received 14 May, 2020; Accepted 7 September, 2020
}

\begin{abstract}
Lack of disability accessible services is commonplace in many African countries. This includes health care, educational, recreational and transportation services amongst many others. In Zimbabwe in particular, the deteriorating socio-economic situation has exposed the glaring insufficiencies of the public transport system. The expression that best describes this situation is neglect and discrimination. This paper illustrates the inaccessibility and discriminatory nature of public transport in Zimbabwe and highlights the causes and consequences of this situation. Mixed qualitative methods including observations and a review of various literature sources have been used to support the assertions made in this paper. The findings discussed here reveal that the discrimination of persons with disabilities emanates from within government structures, thus making it difficult for any progress to be made, as far as developing accessible public transportation services for persons with disabilities.
\end{abstract}

Key words: Disability, Zimbabwe, public transport, discrimination, accessibility.

\section{INTRODUCTION}

While Zimbabwe can be described on paper as having an inclusive society, because it has the right policy framework and has even ratified international conventions such as the United Nations Convention on the Rights of Persons with Disabilities (UNCRPD); the truth is that in practice, the environment is far from inclusive. This paper makes this assertion and uses the issue of public transportation to demonstrate and validate this claim. The paper will thus show the discriminative nature of public transport facilities in Zimbabwe, showing that it is in fact, inaccessible to persons with disabilities. The paper will go further and discuss the root cause of the discriminatory attitudes towards people with disabilities in Zimbabwe. It will also highlight the effects of inaccessible public transport systems on persons with disabilities, emphasizing that this failure in service delivery has far-reaching negative consequences that go beyond mobility limitation, and also include social exclusion, isolation and neglect of persons with disabilities.

E-mail: ndebele.the@gmail.com. Tel: +263778034636.

Author(s) agree that this article remain permanently open access under the terms of the Creative Commons Attribution License 4.0 International License 


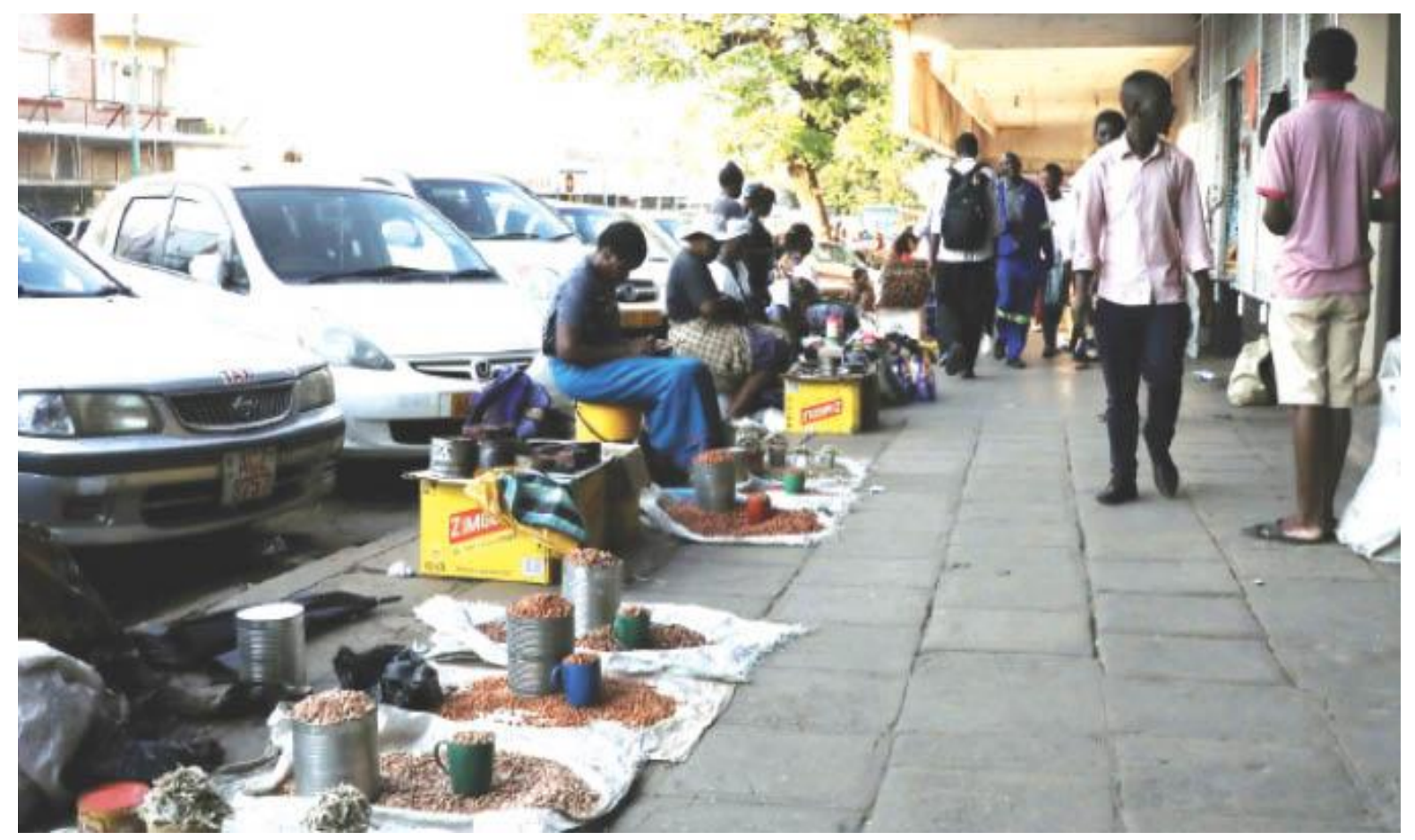

Figure 1. Sidewalk stalls along Herbert Chitepo Street in Bulawayo.

Source: Dube-Moyo (2019).

The impetus for this paper therefore, is to provide a scholastic discussion on the issue that will reach audiences beyond the local Zimbabwean community, in the hope that much needed support can be garnered to help make meaningful change for a population demographic that has been so often overlooked. This paper thus, hopes to stimulate conversation on the need for disability-inclusive transportation services within Africa, more specifically, Zimbabwe.

\section{THE GLARING ISSUE OF PUBLIC TRANSPORT INACCESSIBILITY IN ZIMBABWE}

Persons with disabilities in poor contexts are often deprived of basic services (Eide and Ingstad, 2013). In Zimbabwe in particular, this includes a lack of access to adequate healthcare services, transport services (Daily News, 2020) and other social services. The public transportation system there, excludes and inhibits access by persons with disabilities (Kett and Deluca, 2016). This happens in one of two ways. Firstly, public transport in Zimbabwe is inaccessible because the vehicles used largely in the public transport sector are not modified to allow access for a disabled user, particularly one who has a physical disability. Secondly, inaccessibility is not just an issue of unavailability of suitably modified public transport facilities. It also includes a lack of affordability of the transportation service. The discussions below demonstrate the glaring inaccessibility of public transport in Zimbabwe, providing evidence from observations, literature and media reports.

\section{Inaccessibility as unavailability of suitably modified transportation services}

Over the Christmas holiday period in December 2019, I walked along a street called Herbert Chitepo in Bulawayo, Zimbabwe between sixth and seventh avenue. This section of the city is close to what was used to be the old commuter omnibus rank, Egodini, before it was shut down for re-development. This place has become a hive of activity, with very little space on the sidewalks to walk on because of impromptu sidewalk stalls that line the sidewalk, leaving a narrow pathway, meant to accommodate people walking in both directions, as shown in Figure 1 (Dube-Moyo, 2019).

As I was navigating my way along these sidewalks, I noticed a man in a wheelchair, ahead of me. I was still considering the inconvenience that he must have been experiencing, moving along the sidewalk, as it was particularly packed on that day, with lots of foot traffic. He was able to push himself along for a couple of metres, 


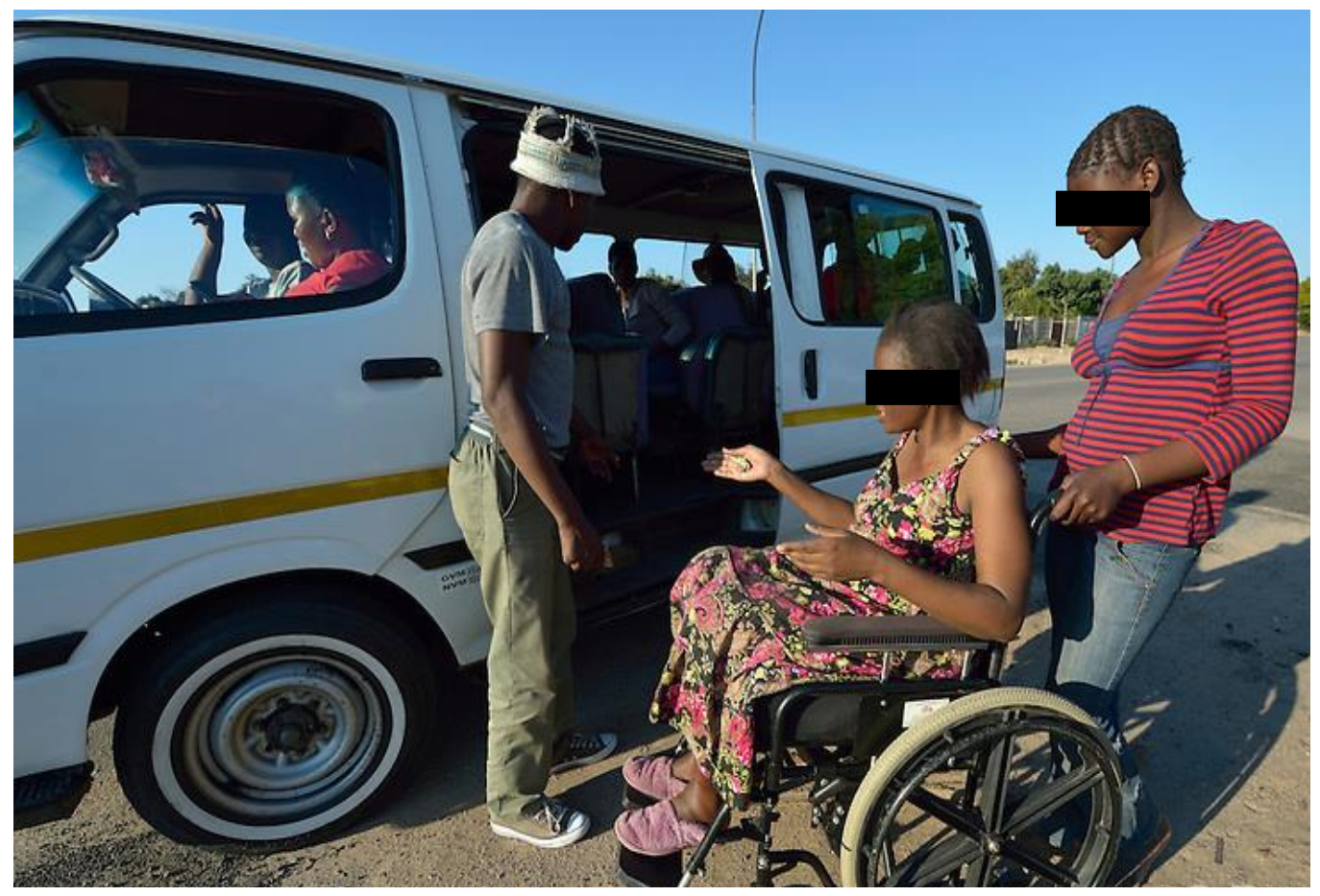

Figure 2. The disability inaccessible commuter omnibus in Zimbabwe. Source: Jeffrey (2014)

after which, he would stop, and the street vendors would attempt to move their wares, just so that they could widen the sidewalk just that little bit, allowing him to continue with his trip. As I was still processing this image, I then realised that the man ahead of me was heading towards a kombi (a commuter minibus). Figure 2 clearly shows what the commuter omnibuses look like, and exactly how they are inaccessible for persons with disabilities.

I wondered what the procedure was going to be for him to get onto the commuter omnibus. So, I took a moment to see exactly how he was going to get inside. The man approached the conductor, and had a brief conversation with him, after-which, the kombi conductor looked to one of the other passengers to ask him for assistance to lift the man in the wheelchair into the kombi. They placed him in the seat nearest to the kombi door. Once they had done that, the conductor took the foldable wheelchair and placed it in the boot. While that situation seemed to have been solved, it was disheartening to see the indignity the public transport services impose on persons with disabilities. This situation while unfortunate, is also illegal, considering that section 22 of the Zimbabwean Constitution makes specific provision for the treatment of persons with disabilities with dignity and respect (Government of Zimbabwe, 2013).

Around July of 2019, there was a glimmer of hope that the public transportation situation would improve for persons with disabilities. During that time, the President of Zimbabwe announced to the citizens, that the government would procure buses that would ease the transport challenges of the citizens (Global Accessibility News, 2019). Unfortunately, the new buses do not have the necessary modifications that enable access for disabled persons, as demonstrated in Figure 3 (Harare Live, 2019); so much so that most people with disabilities opt for kombis that cost more than the buses in general.

I will admit, because I had seen decent accessible public transportation options in other developed countries, I found it infuriating that even in this era of advanced technologies and constant information sharing, that kombis are the main mode of transport, and yet they are highly inaccessible especially for the individual with physical disabilities. However, to add on to the problem of unavailability of suitable public transport, persons with disabilities also contend with excessive charges when using public transportation.

\section{Inaccessibility as unaffordability}

As already indicated, accessibility also relates to affordability. Wheelchair users in Zimbabwe are sometimes charged double fares so as to accommodate them, and their mobility aids (Jeffrey, 2014). This 


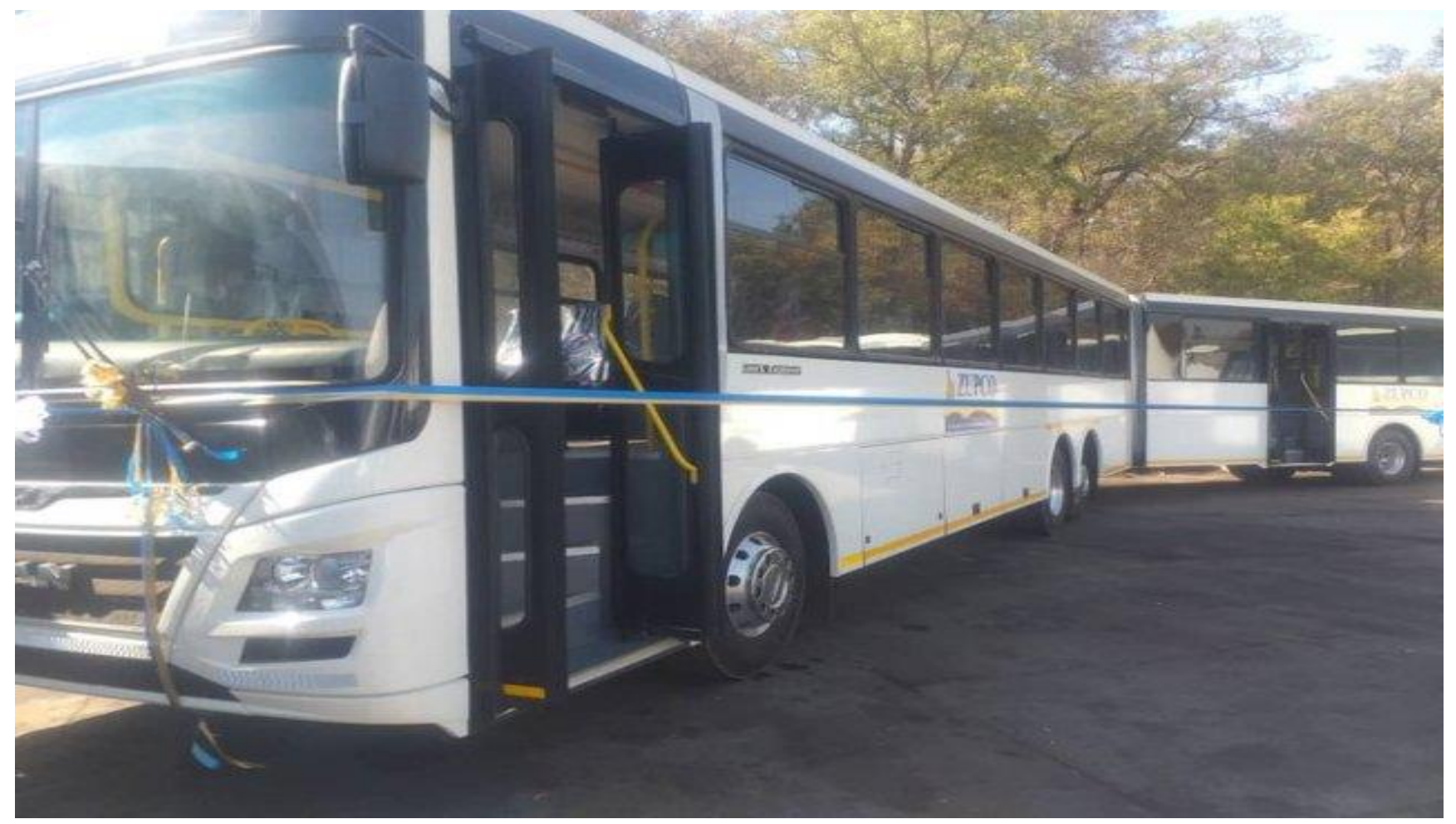

Figure 3. The recently purchased disability inaccessible buses in Zimbabwe. Source: Harare Live (2019).

prejudices persons with disabilities who are often also financially and economically disadvantaged (United Nations High Commission for Refugees, 2013). In most countries, governments step in to provide fare concessions for persons with disabilities and other disadvantaged persons. This is not necessarily the case in Zimbabwe. While the buses that were procured by the government to ease the public transport crisis in Zimbabwe charge relatively low fares, because of a subsidy received from the government; they are often overcrowded, so much so, as already mentioned, that persons with disabilities opt for the less crowded, also inaccessible exorbitant kombis (Global Accessibility News, 2019). The cost barriers compound the inaccessibility issue, making persons with disabilities less likely to commute, thus limiting their mobility, because in this instance unaffordability of the public transport makes it inaccessible. Thus, these levels of discrimination towards persons with disabilities in Zimbabwe leave them contending with both unavailability and unaffordability of public transport. Questions then arise as to why this current discrimination in service provision prevails. Is the transport inaccessibility problem known to government? Or is the government itself discriminating against persons with disabilities?

\section{Is the transport inaccessibility problem known to government?}

In the past, the issue of inaccessible public transport systems in Zimbabwe has been discussed in opinion columns of local Zimbabwean newspapers such as the Chronicle, and The Herald, and the Daily News. The Chronicle and The Herald are government publications, and thus indicating that the issue of poor public transportation is a known one, even within government. There is other evidence from the media which indicates that this is a well-known and publicised issue within Zimbabwe, and yet the public transportation system in the country still excludes persons with disabilities because of its inaccessibility. For instance, Dr. Joshua Malinga, a special advisor on disability issues in the President's Office, was quoted stating that one of the common complaints government has received from persons with disabilities, is that of a lack of accessible public transport (Mabika, 2019). Similarly, one Member of Parliament, the late Miriam Mushayi was quoted by a media outlet acknowledging that public services in Zimbabwe are not disability friendly, and that the issue of transport was critical, especially since the newly procured buses are also not disability friendly (Global Accessibility 
News, 2019).

In another instance showing that the public transportation woes of persons with disabilities are known to government, at an event in Bulawayo in July of 2019, where President Emmerson Mnangagwa was delivering some buses to add to the public transport fleet, he was quoted saying that his Government would source appropriate buses for people with disabilities. In the interim, he pledged that necessary modifications would be made to the current fleet to ensure that citizens with disabilities would conveniently board and alight from the buses (Madzimure and Ruzvidzo, 2019). These instances above, demonstrate that government is knowledgeable on the need for more accessible and inclusive public transportation services, and the plight of persons with disabilities. To the extent that this is true, the question then would be, why does the issue continue to be ignored? Is the Zimbabwean government deliberately discriminative of persons with disabilities, given that it is well-informed of the service gaps that affect them?

\section{Discrimination starts at government levels: evidence from literature and the media}

The glaring nature of the inaccessibility of public transport facilities for people with disabilities in Zimbabwe raises concerns as to why the situation has not been addressed. Evidence from literature and the media indicates what can be concluded to be deliberate discriminatory action by government itself, which has relegated persons with disabilities to a second-class citizen status. The government has taken persons with disabilities for granted. For instance, Zimbabwe has close to 1.4 million people living with a disability, and this equates to just over $8 \%$ of the population, and yet still the public transportation services in Zimbabwe are not accessible to people with disabilities (Watson, 2018) and this has denied them independence. Is it that government feels $8 \%$ of the population is not a large enough figure to act? Or is it perhaps the usual attitude of the Zimbabwean government, to continuously make promises and just never meet them?

In Zimbabwe, officials are in the habit of saying something, but never really implementing what they say. For instance, in January 2019, in a radio interview, the Zimbabwean Minister of Public Service, Labour and Social Welfare at the time, $\mathrm{Dr}$ Sekai Nzenza was speaking on her intentions for her ministry. The crux of her message was that persons with disabilities should not be treated like second class citizens, and that she personally takes disability issues very seriously. She hinted at a lack of disability awareness in the nation and spoke of a need to sensitize the nation on issues to do with disability, because persons with disabilities in Zimbabwe are stigmatised. Her conversation with the radio host inspired hope that perhaps she may in fact help usher in a culture of respect and appreciation for persons with disabilities in the country. Following this interview, I went onto the Ministry's webpage, to get a sense of what else the ministry is doing, or will be doing regarding the affairs of persons with disabilities, and to my disappointment, the link to the department for persons with disabilities was the only one that did not lead to a page about the department. All other links to other departments led to the department pages. I followed up on this page a year later in May of 2020, and still, there was no page for disabled persons affairs, and still no information on what services are provided for persons with disabilities by the ministry. However, as of September 2020, there have been some developments, and there is now a Disabled Persons Affairs webpage. While this is a positive step, it can also be used to reinforce the assertion that issues relating to disabled persons are relegated to the sidelines, particularly because it has taken over a year for this government ministry to rectify this issue.

Another example showing discrimination at government levels is that of the consistent failure by government to get rid of the kombi system, which has been touted by academics and citizens alike, as being unsafe. Several politically motivated changes have been made in the public transport sector in Zimbabwe, such as the reintroduction of the buses by the Zimbabwe United Passenger Company (ZUPCO) in January of 2019, and yet even after public proclamations by the President and government officials to ensure modification of these buses, to make them disability accessible, the buses are still inaccessible, especially to the passenger with a physical disability. A lot of the hype has been about affordability and not accessibility. ZUPCO is a parastatal company in Zimbabwe, which operates urban and long-distance bus routes (Murenzvi, 2019), and by that characteristic alone, part of its mandate should be to ensure transport accessibility for all, but that is still yet to be seen, given that a year into the re-introduction of these buses, they are still not disability-accessible.

The issue with public transportation in Zimbabwe is that all measures that are introduced all seem to be politically inclined, never really taking cognisance of the requirements of the population, especially not those of persons with disabilities. For instance, even though buses were re-introduced, there is no indication that government will put an end to the kombis, which are unsafe, not only for passengers with disabilities, but also for their non-disabled counterparts. Kombis are reportedly involved in a majority of Zimbabwe's road accidents, that either leave passengers deceased or disabled (Muvuringi, 2012; Muzavazi, 2017), and yet because kombi drivers are a considerable voting bloc (Kett and Deluca, 2016), the kombis are still unfortunately the most dominant mode of public transportation in the country. The failure by government to decidedly phase out the kombis, which are not only dangerous, but also 
inaccessible, is yet another example of the discriminatory attitude of government towards persons with disabilities.

In another incident demonstrating a blatant disregard for the rights of persons with disabilities to accessible public transportation, the President of Zimbabwe purchased buses that are not disability accessible. Upon delivery of these buses to ZUPCO, in April of 2019, he noted that his government would work to ensure that all the people of Zimbabwe would be able to access this public transportation facility (Machaya, 2019). However, in July of that same year, another consignment of buses was received, and those too, are inaccessible for persons with physical disabilities, and as of April 2020, they have yet to get the necessary modifications to make them accessible.

In 2015, the Vice-President of the country at that time, Phelekezela Mphoko was reported to have made a statement to the effect that, the jobs in the informal sector such as street vending, are meant to be for persons with disabilities (Daily News, 2015). This statement not only displayed the discriminatory nature of the government, but also reinforced negative stereotypes that persons with disabilities are 'unable' to perform other professional roles, on account of their disabilities. While the rights of Persons with disabilities should be protected by the Disability Act, of 1992, the government does not seem to act on gross and blatant disregard of their rights, case and point, no accessible public transport options. To add to it, Zimbabwe ratified the UNCRPD in 2013, a move which brought hope of a better life for persons with disabilities, but alas, the situation has remained unchanged, and kombis are still the order of the day.

On paper, Zimbabwe appears to have all the right policies in place to ensure that the rights of persons with disabilities are protected, so much so that the state of disability policy has been described as being almost close to an inclusive policy (Kett and Deluca, 2016). However, on the ground, the situation tells of a different story, one where the rights of persons with disabilities are in fact disregarded by the government itself, and where there has been no action towards materialising these policies. This near-miss situation not only perpetuates the exclusion of persons with disabilities, but also has other adverse effects that go beyond more than just limiting movement.

\section{The impact of inaccessible public transport}

While a limitation of movement is the most glaring consequence of inaccessible public transportation, there are other effects. Movement constraints exacerbate social isolation of persons with disabilities (The World Bank, 2015). Some of the other effects include social exclusion (Bezyak et al., 2017), stripping of dignity, fear (Coffey, 2018), physical harm (Chiwanga, 2017) and low self-esteem. Furthermore, movement restriction makes accessing social amenities such as, health care, education, housing, and community life challenging, and yet disabled persons are reported to already experience high rates of poverty and poor health, low educational achievements and few employment opportunities (Meekosha and Soldatic, 2011). Thus, a movement restriction will also compound these issues.

In Zimbabwe in particular, one of the effects of inaccessible public transport is that of physical injury (Chiwanga, 2017). Because persons with disabilities must be lifted in and out of these kombis, some of them end up with injuries, whilst the process itself of being lifted and moved around, with other passengers watching on, also strips them of their dignity.

These traumatic experiences not only strip persons with disabilities of their dignity, but also instil a social anxiety, fear and low self-esteem (Tillman et al., 2013). There is also a growing misconception of disabled passengers as being 'difficult' because of the amount of time it takes for them to embark and disembark, and these negative perceptions about them, by both public transport operators and passengers alike, have sometimes resulted in them being denied access onto the public transit systems, or just being poorly treated by fellow passengers (Coffey, 2018).

The scenarios above, are not only a travesty of justice, but also lag grossly behind the global sustainable development goals (SDGs), which have become the benchmark for development into the future, for all countries. They emphasize the need for the development of sustainable modes of transport if countries are to achieve these goals (United Nations General Assembly, 2017),

\section{CONCLUSION}

While the global sustainable development goals agenda has provided a vision of a future world that is inclusive, and guidelines on how to achieve that vision, there are governments such as that of Zimbabwe, that appear to have ignored that guidance, opting instead, to follow a path that perpetuates exclusion of other population demographics, such as persons with disabilities. In a country that has had no accessible public transport ever, and there is an acknowledgement of a need for disabilityaccessible buses, why would a purchase of new inaccessible buses be made? These transportation difficulties experienced by persons with disabilities in Zimbabwe are in fact symptomatic of a bigger problem, that of discrimination at government and national leadership levels, which appear to consistently relegate persons with disabilities and their needs. This deliberate neglect is inexcusable and is a violation of human rights. Transportation and mobility play an important part in facilitating societal participation for people with disabilities. Thus, travel should not be a barrier to 
independence. There is a need to re-engage government, non-profits and the public transport associations on the issue of disability accessible transportation in Zimbabwe. There are clearly some local laws and policies in place, and even international conventions that are meant to guide the implementation of such an exercise, and yet, the country is still laden with a kombi system that excludes and often dehumanizes persons with disabilities, while stripping them of their dignity. In addition, societal attitudes remain a significant barrier for people with disabilities. Failure to provide this essential service for persons with disabilities perpetuates their exclusion from mainstream society, whilst also reinforcing discriminative practices. It is therefore imperative that this hazardous and restrictive public transportation system is discarded, and new, inclusive, safer alternatives are adopted, that will allow for enhanced quality of life for all citizens. After all, everyone is entitled to movement, and to a preservation of their dignity.

\section{CONFLICT OF INTERESTS}

The author has not declared any conflict of interests.

\section{REFERENCES}

Bezyak JL, Sabella SA, Gattis RH (2017). Public Transportation: An Investigation of Barriers for People with Disabilities. Journal of Disability Policy Studies. Journal of Disability Policy Studies 28:1. doi:10.1177/1044207317702070

Chiwanga S (2017). Zimbabwe public transport system not safe and accessible to people with disabilities. (The Chronicle) Retrieved April 25, 2020, from https://www.chronicle.co.zw/zimbabwe-publictransport-system-not-safe-and-accessible-to-people-with-disabilit

Coffey H (2018). One in Four Disabled People Don't Use Public Transport Due to Negative Attitudes From Other Passengers, New Research Finds. (Independent) Retrieved April 25, 2020, from https://www.independent.co.uk/travel/news-and-advice/uk-disabledtravel-accessibi

Daily News (2015). Govt Must Implement Disability Inclusive Actions. (Daily News) Retrieved February 28, 2020, from https://dailynews.co.zw/articles-2015-02-21-govt-must-implementdisability-inclusive-actions/

Daily News (2020). Disabled Bemoam Lack of Access to Healthcare. (Daily News) Retrieved February 28, 2020, from https://dailynews.co.zw/articles-2020-01-01-disabled-bemoan-lack-ofaccess-to-health-care/

Dube-Moyo Y (2019). Food vending now a public health issue. (Chronicle) Retrieved April 09, 2020, from https://www.chronicle.co.zw/food-vending-now-a-public-health-issue/

Eide A, Ingstad B (2013). Disability and poverty - Reflections on research experiences in Africa and beyond. African Journal of Disability 2(1):31. doi:10.4102/ajod.v2i1.31
Global Accessibility News (2019). Zimbabwe: People Living With Disability Call for an Inclusive Public Transport System. (Global Accessibility News) Retrieved March 20, 2020, from http://globalaccessibilitynews.com/2019/11/20/zimbabwe-peopleliving-with-disability-call-for-an-inclusive-public-transport-system/

Government of Zimbabwe (2013). Constitution of Zimbabwe Amendment (No. 20) Act. Harare: Government Printer.

Harare Live (2019). See Pictures President Mnangagwa Commissions 47 New ZUPCO Buses. (Harare Live) Retrieved April 20, 2020, from https://hararelive.com/2019/07/31/see-pictures-presidentmnangagwa-commissions-47-new-zupco-buses/

Jeffrey P (2014). Kairos Photos - Images by Paul Jeffrey. (Kairos Photos) Retrieved February 26, 2020, from https://kairosphotos.photoshelter.com/image//0000B_GNd5vA7.g

Kett M, Deluca M (2016). Transport and Access to Inclusive Education in Mashonaland West Province, Zimbabwe. Social Inclusion 4(3):6171. doi:10.17645/si.v4i3.502

Mabika C (2019). Zimbabwe: Don't Discriminate Against the Disabled, Says Malinga. (All Africa) Retrieved March 04, 2020, from https://allafrica.com/stories/201902270249.html

Machaya P (2019). ZUPCO gets 28 new buses, Mnangagwa says life to be 'easier'. (ZimLive) Retrieved April 2020, 2020, from https://www.zimlive.com/2019/04/16/zupco-gets-28-new-busesmnangagwa-says-life-to-be-easier/

Madzimure J, Ruzvidzo W (2019). Zupco grows . . .President commissions 47 new buses. (The Chronicle) Retrieved April 24 2020, from https://www.chronicle.co.zw/zupco-grows-presidentcommissions-47-new-buses/

Meekosha H, Soldatic K (2011). Human Rights and the Global South: the case of disability. Third World Quarterly, 32(8): 1383-1398. doi:10.1080/01436597.2011.614800

Murenzvi M (2019). All aboard Zupco: Is this a rebirth or stillbirth? (NewsDay) Retrieved April 20, 2020, from https://www.newsday.co.zw/2019/02/all-aboard-zupco-is-this-arebirth-or-stillbirth/

Muvuringi PM (2012). Road Traffic Accidents in Zimbabwe, Influencing Factors Impact and Strategies. University of Amsterdam, Department of Public Health. Amsterdam: Unpublished Dissertation.

Muzavazi (2017). Efficient, safe transport system a necessity. (The Herald) Retrieved April 20, 2020, from https://www.herald.co.zw/efficient-safe-transport-system-a-necessity/

The World Bank (2015). For Persons with Disabilities, Accessible Transport Provides Pathways to Opportunity. (World Bank Group) Retrieved April 24, 2020, from http://www.worldbank.org/en/news/feature/2015/12/03/for-personswith-disabilities-accessible-transport-provides-pathways-

Tillman V, Haveman M, Stoppler R, Kvas S, Monninger D (2013). Public bus drivers and social inclusion: Evaluation of their knowledge and attitudes toward people with intellectual disabilities. Journal of Policy and Practice in Intellectual Disabilities 10(4):307-313. doi:10.1111/jppi.12057

United Nations General Assembly (2017). Strengthening the links between all modes of transport to achieve. Geneva: United Nations. Retrieved from https://undocs.org/en/A/RES/72/212

United Nations High Commission for Refugees (2013). People with Disabilities. Geneva: United Nations.

Watson J (2018). Accessibility Rights of Disabled Children in Zimbabwe Schools. (New Zimbabwe) Retrieved March 03, 2020, from https://www.newzimbabwe.com/accessibility-rights-of-disabledchildren-in-zimbabwe-schools/ 